\title{
ADMINISTRAÇÃO DE ANTIBIÓTICO EM POEDEIRAS SEMIPESADAS DURANTE O PROCESSO DE DEBICAGEM
}

\author{
ANTIBIOTIC ADMINISTRATION IN LAYING HENS DURING THE BEAK \\ TRIMMING PROCESS
}

\author{
Gonçalves, F.M. ${ }^{1 *}$, Gentilini, F.P. ${ }^{1}$, Anciuti, M.A. ${ }^{2}$, Lopes, D.C.N. ${ }^{1}$, Peters, M.D.P. ${ }^{1}$, Rutz, F. ${ }^{1}$, \\ Cardellino, R.A. ${ }^{1}$, Manzke, N. ${ }^{3}$, Xavier, E.G. ${ }^{1}$ e Zanusso, J.T. ${ }^{1}$
}

\begin{abstract}
1'Departamento de Zootecnia. Faculdade de Agronomia Eliseu Maciel. Universidade Federal de Pelotas. Campus Universitário s/n. CEP 96010-900.Pelotas, RS. Brasil. *fmedeiros_fv@ufpel.edu.br ${ }^{2}$ Conjunto Agrotécnico Visconde da Graça. Universidade Federal de Pelotas. Av. Ildefonso Simões Lopes, 2791. Cx. Postal 460. CEP 96060-290. Pelotas, RS. Brasil.

${ }^{3}$ Faculdade de Medicina Veterinária. Universidade Federal de Pelotas. Campus Universitário s/n. CEP 96010-900. Pelotas, RS. Brasil.
\end{abstract}

\section{PALAVRAS CHAVE ADICIONAIS}

Sulfadiazina+trimetoprim. Ganho médio de peso. Consumo alimentar. Contaminação. Bem-estar animal.

\section{RESUMO}

A debicagem é amplamente utilizada na indústria avícola com os objetivos de reduzir o canibalismo e o desperdício de ração pelas aves. O objetivo do experimento foi verificar a resposta das aves com a utilização de antibiótico via água durante o processo de debicagem. Um total de 2384 poedeiras semipesadas foi submetido à debicagem aos sete dias de idade e divididos em dois grupos: T1: controle e T2: com administração de antibiótico. Foram avaliadas as variáveis de consumo alimentar, peso corporal médio, ganho médio de peso, e conversão alimentar. Não foi observada diferença estatística entre os tratamentos para nenhuma das variáveis em questão. A administração de antibióticos não favorece o crescimento e consumo de aves submetidas a debicagem.

\section{SUMMARY}

Debeaking is widely used in layer operations to reduce cannibalism and waste of feed. This study aimed to investigate the use of antibiotics in water during the period of debeaking. A total of 2384 birds were debeaked at 7 days of age and divided into two groups. The T1: control and the T2: antibiotic-administered group. Feed intake, avera-

Recibido: 20-12-07. Aceptado: 17-1-08.

\section{Additional KeYWORDS}

Sulfadiazin+trimetoprim. Weight gain average. Feed intake. Contamination. Animal welfare.

ge of body weight, weight gain and feed conversion were evaluated. The results indicated that adding antibiotic in the water during the debeaking period has no effect on performance of pullets.

\section{INTRODUÇÃO}

Ainda que a debicagem seja amplamente praticada na indústria avícola, tal prática vem sendo estudada por pesquisadores e órgãos não governamentais defensores do bem-estar animal em sistemas intensivos de produção, identificando o método como desumano (Harrison, 1964; citado por Davis et al., 2004), introduzindo-o a lista de práticas de manejo a serem banidas em um futuro bem próximo. Dados de literatura apontam uma redução no consumo e uma melhor conversão alimentar, bem como diminuição do canibalismo em aves debicadas, comprovando a necessidade em utilizar-se a prática em um sistema de produção de ovos (Glatz, 2000).

$\mathrm{O}$ ato de bicar das aves dominantes no 
plantel provoca um estresse crônico nas demais, diminuindo o consumo e piorando a conversão alimentar, prejudicando índices produtivos e, até mesmo, afetando a qualidade interna e externa dos ovos.

Técnicas mais modernas com o objetivo de reduzir o sofrimento, como a debicagem a laser, já estão disponíveis porém, com elevado custo de aquisição pela tecnologia agregada ao equipamento. França et al. (2007) observaram maior competitividade em sistemas de integração de frangos de corte criados sob condições tecnológicas superiores em relação aos sistemas não automatizados de criação, indicando que a lucratividade dos sistemas relaciona-se com o nível tecnológico empregado nos mesmos.

A incisão exagerada do bico da ave bem como a utilização da lâmina cortante a uma temperatura abaixo do recomendado prejudica a cauterização do bico da ave, permanecendo uma via de acesso para microorganismos. $\mathrm{O}$ nível mais alto de controle do consumo é desempenhado pelo hipotálamo, o qual possui dois centros de regulação estimulados por diversos fatores: os extrínsecos são os mais associados ao processo de debicagem. Qualquer interferência nos receptores de apreensão, encontrados no bico da ave, provocará uma resposta neste centro regulatório (Macari et al., 2002).

Jongman e Barnett (2005) afirmam que a debicagem sempre irá causar alteração no sistema sensorial do bico das aves.

Sulfas em geral e trimetoprim são classificados como antimicrobianos quimioterápicos, atuando sobre agentes causadores de processos infecciosos nos animais. Entretanto, ao avaliarem a resistência e sensibilidade de cepas de E. coli isoladas de frangos de corte, Araújo et al. (2005), identificaram um percentual de $66,7 \%$ de resistência a combinação sulfametrol trimetoprim, demonstrando que doses subterapêuticas selecionam os agentes e não debelam a infecção.

Não existem estudos sobre a utilização de antimicrobianos em práticas de debi- cagem e possível favorecimento da resposta zootécnica dos animais submetidos a tal manejo.

O objetivo deste estudo é avaliar o efeito da administração de antibiótico via água em poedeiras submetidas ao processo de debicagem.

\section{MATERIALE MÉTODOS}

O estudo foi realizado no aviário experimental pertencente a Universidade Federal de Pelotas, em um período de 14 dias. Um total de 2384 poedeiras da linhagem Isa Brown foi alojado e distribuído em aviário tipo dark house com um dia de idade. As dietas foram fornecidas à vontade com níveis nutricionais estabelecidos pelo manual da linhagem. Os tratamentos consistiram em: T1: sem antibiótico e T2: com antibiótico. O medicamento utilizado foi a base de sulfadiazina e trimetoprim, de uma marca comercial indicada para o uso avícola. O delineamento experimental utilizado foi o completamente ao acaso e o modelo estatístico adotado foi o $\mathrm{Y}_{\mathrm{ij}}=\mu+\mathrm{T}_{\mathrm{i}}+\mathrm{e}_{\mathrm{ij}}$. As variáveis de desempenho observadas foram: ganho médio de peso (GMP), peso corporal médio aos sete dias e aos 14 dias (PC7 e PC14, respectivamente), consumo alimentar médio na primeira e segunda se-

Tabela I. Peso corporal (PC) aos 7 e 14 dias de idade e ganho de peso (GP) de poedeiras semipesadas submetidas à debicagem com ou sem administração de antibiótico. (Body weight in 7 and 14 days of age and weight gain of debeaked layers with or without antibiotic administration).

\begin{tabular}{lccc}
\hline & \multicolumn{2}{c}{$P C(g)$} & GP \\
& 7 dias & 14 dias & $(g)$ \\
\hline T1 & 59,04 & 99,77 & 40,99 \\
T2 & 58,76 & 100,73 & 41,96 \\
Teste $F(p=)$ & 0,4356 & 0,2202 & 0,4958 \\
CV $(\%)$ & 15,1 & 18,81 & 4,16 \\
$\mathrm{R}^{2}$ & 0,0003 & 0,0007 & 0,097 \\
\hline
\end{tabular}




\section{ANTIBIÓTICO PARA POEDEIRAS DURANTEADEBICAGEM}

mana de vida (CSA1 e CSA2, respectivamente) e conversão alimentar média (CA). Os dados foram submetidos a ANOVA $(\mathrm{p}<0,05)$.

No terceiro dia, separaram-se as pintainhas em oito círculos de proteção cada um representando uma repetição, designando-as aos tratamentos, aleatoriamente. A administração do antibiótico via água de beber foi realizada no sexto, sétimo e oitavo dia de idade. As pintainhas foram debicadas no sétimo dia, com debicador de lâmina cortante à temperatura de $600^{\circ} \mathrm{C}$. As pesagens dos animais foram semanais e individuais. A ração foi pesada no início de cada semana e as sobras no final de um intervalo de sete dias, para avaliação do CSA. O GMP foi obtido através da fórmula: $\mathrm{GMP}=\mathrm{PC} 14$ - PC7. O valor de CA foi obtido pela divisão do CSA pelo GMP.

\section{RESULTADOSEDISCUSSÃO}

Os dados na tabela I indicam que a administração de antibiótico, não promoveu maior peso corporal aos sete e quatorze dias de idade ( $\mathrm{p}>0,05)$. Davis et al. (2004) testaram dois períodos de debicagem observando maior peso corporal na segunda semana de vida $(\mathrm{p} \leq 0,0001)$ nas aves não submetidas a esse manejo. Dipeolu et al. (2005) avaliaram o desempenho de poedeiras adultas suplementadas com enzimas e antibióticos ou somente enzimas e encontraram maiores índices de ganho de peso nas primeiras.

O consumo alimentar médio na primeira e segunda semana de vida não foi influenciado pelos tratamentos (tabela II), não havendo

\section{BIBLIOGRAFIA}

Araújo, L.F., Café, M.B., Leandro, N.S.M., Junqueira, O.M., Araújo, C.S.S., Cunha, M.I.R. e Silva, C.C. 2005. Desempenho de poedeiras comerciais submetidas ou não a diferentes métodos de debicagem. Cienc. Rural, 35:169173.

Bell, D., Chase, B., Douglas, A., Hester, P., Mench, J., Newberry, R., Shea-Moore, M., Stanker, L.,
Tabela II. Consumo alimentar médio (CSA) na primeira e segunda semana de idade, e conversão alimentar média (CA) durante o periodo. (Average feed intake in the first and second week of age, and feed/gain ratio during the period).

\begin{tabular}{lccc}
\hline & \multicolumn{2}{c}{ CSA $(\mathrm{g})$} & $\mathrm{CA}$ \\
Tratamento & 1 $^{\text {a }}$ semana & $2^{\mathrm{a}}$ semana & $(\mathrm{kg} / \mathrm{PV})$ \\
\hline $\mathrm{T} 1$ & 13110,7 & 41150,0 & 1330,7 \\
$\mathrm{~T} 2$ & 13210,0 & 47884,5 & 1456,3 \\
Teste $\mathrm{F}(\mathrm{p}=)$ & 0,8008 & 0,1925 & 0,3728 \\
$\mathrm{CV}(\%)$ & 3,71 & 13,01 & 11,98 \\
$\mathrm{R}^{2}$ & 0,013 & 0,31 & 0,16 \\
\hline
\end{tabular}

indícios que a administração de antibiótico concomitantemente com a debicagem possa influenciar a variável em questão. A conversão alimentar também não se mostrou diferente entre os tratamentos $(p>0,005)$, porém, para as aves que receberam o antibiótico (T1), a conversão foi numericamente menor. Davis et al. (2004) verificaram um maior consumo alimentar na segunda semana de vida em aves não debicadas comparando-as a poedeiras submetidas a tal prática. De acordo com Bellet al. (2004), a habilidade da ave em alimentar-se fica prejudicada temporariamente, uma vez que deve haver uma readaptação à nova forma do bico.

\section{CONCLUSÃO}

A administração de antibiótico via água não exerce efeitos significativos no ganho de peso, consumo e conversão alimentar em poedeiras semipesadas submetidas ao processo de debicagem.
Swanson, J. and Armstrong, J. 2004. UEP uses scientific approach in its establishment of welfare guidelines. Feedstuffs, 76:13-21.

Davis, G.S., Anderson, K.E. and Jones, D.R. 2004. The effects of different beak trimming techniques on plasma corticosterone and performance criteria in Single Comb White Leghorn Hens. Poultry Sci., 83: 1624-1628. 


\section{GONÇALVES ETAL.}

Dipeolu, M.A., Eruvbetine, D., Oguntona, E.B., Bankole, O.O. and Sowunmi, K.S. 2005. Comparison of effects of antibiotics and enzyme inclusion in diets of laying birds. Arch. Zootec., 54: 3-11.

França, L.R. de, Souza, J.G. e Moraes, V.M.B. 2007. Comparação de dois modelos de produção de frangos de corte. Arch. Zootec., 56: 359362.

Glatz, P.C. 2000. Review of beak-trimming methods. Rural Industries Research \& Development
Corporation, 72: 1-29

Jongman, E.C. and Barnett, J.L. 2005. Physiological and behavioral aspects of beak-trimming in poultry. Poultry welfare issues. In: $C A B$ Abstracts. http://www.cababstractsplus.org/ google/abstract.asp?AcNo=20053093951. (2611-2007).

Macari, M., Furlan, R.L. e Gonzáles, E. 2002. Ingestão de alimentos: Mecanismos regulatórios. Fisiologia aviária aplicada a frangos de corte. Ed. Funep/UNESP. Jaboticabal, SP. 2: 187-192.

Archivos de zootecnia vol. 59, núm. 226, p. 298. 